\title{
Flexible ruthenium oxide-activated carbon cloth composites prepared by simple
} electrodeposition methods

\author{
J.M. Sieben ${ }^{1}$, E. Morallón ${ }^{1, *}$, D. Cazorla-Amorós ${ }^{2}$ \\ ${ }^{1}$ Departamento de Química Física e Instituto Universitario de Materiales, Universidad de \\ Alicante, Ap. 99 Alicante, España. \\ ${ }^{2}$ Departamento de Química Inorgánica e Instituto Universitario de Materiales, Universidad de \\ Alicante, Ap. 99 Alicante, España
}

\begin{abstract}
This work focuses on the preparation of flexible ruthenium oxide containing activated carbon cloth by electrodeposition. Different electrodeposition methods have been used, including chronoamperometry, chronopotentiometry and cyclic voltammetry. The electrochemical properties of the obtained materials have been measured. The results show that the potentiostatic method allows preparing composites with higher specific capacitance than the pristine activated carbon cloth. The capacitance values measured by cyclic voltammetry at $10 \mathrm{mV} \mathrm{s}^{-1}$ and $1 \mathrm{~V}$ of potential window were up to 160 and $180 \mathrm{~F} \mathrm{~g}^{-1}$. This means an improvement of $82 \%$ and $100 \%$ with respect to the capacitance of the pristine activated carbon cloth. This excellent capacitance enhancement is attributed to the small particle size $(4-5 \mathrm{~nm})$ and the three-dimensional nanoporous network of the ruthenium oxide film which allows reaching very high degree of oxide utilization without blocking the pore structure of the activated carbon cloth. In addition, the electrodes maintain the mechanical properties of the carbon cloth and can be useful for flexible devices.
\end{abstract}

\section{Corresponding Author}

*E. Morallon, morallon@ua.es, Telf. +34-965909590 


\section{Introduction}

The rapid population growth, economic expansion and industries development has increased the global energy consumption. Today, fossil fuels (oil, gas and coal) supply around $85 \%$ of the energy market, providing more than $80 \%$ of the carbon dioxide anthropogenic emissions released into the atmosphere each year. As a result, the present energy system could not be able to sustain the global economic growth in a relative short period of time [1]. In this scenario, the government's efforts are focused on the development of sustainable solutions that include the replacement of fossil fuels by renewable energy sources, efficiency improvements in the energy production and energy savings on the demand side in order to reduce the carbon emission and to mitigate the global warming consequences (i.e., global climate change and level sea rise) [2]. However, many of the renewable energy sources are of a fluctuating nature and cannot cover the daily electricity consumption of industries, households/services and transport activities [3]. To solve this limitation, an efficient storage device can be employed in order to cover the power consumption during the low/zero period of energy production or during a peak power demand $[4,5]$.

One of the most important challenges facing scientists today is the construction of efficient systems that can store the energy produced by renewable sources and make it available according to the demand. In this respect, supercapacitors have attracted great attention because they can be used for large commercial applications ranging from small electronic devices as cell phones and emergency medical equipment to electric vehicles and photovoltaic cells [6]. For instance, supercapacitors can be used to recuperate the breaking energy in electric buses [7] and electric/fuel cell cars [8] or to storage the excess of energy produced by wind turbines [5]. 
However, their limited energy density restricts their use to electrical systems that require a certain power for only a few seconds $[9,10]$. Hence, further efforts should be focused on the design of new materials that can maintain the high power and increase the energy density. For this reason, an intense investigation is been carried out in order to optimize the performance of the materials employed as electrodes [9,11]. In addition, in the case of portable electronic equipments, the need of flexible and compact energy storage systems is mandatory and it remains as a challenge to be solved [12,13].

Different technologies and materials have been used to manufacture supercapacitor electrodes [6,9]. Porous carbon materials are very attractive for energy storage due to their high porosity, good electrical conductivity and remarkable chemical stability in diverse electrolyte solutions. Furthermore, the possibility of using the activated carbon without binder, for example cloths or felts, provides additional benefits such as flexibility, avoidance of the use of any binder and conductivity promoter and high density, what can be helpful to produce compact capacitors.

Many transition-metal oxides, such as $\mathrm{RuO}_{2}[15-18]$ and $\mathrm{MnO}_{2}$ [14, 19-21], have been studied extensively for this application because they have high capacitance, and high electrical conductivity. Ruthenium oxide is the most promising oxide because of its high theoretical capacitance (1358 $\mathrm{F} \mathrm{g}^{-1}$ ), low electrochemical series resistance (ESR) and long cycle life. However, its capacitance decreases rapidly at high scanning rates due to the saturation and reduction of protons in the electrolyte-electrode interface during cycling. Furthermore, the massive utilization of $\mathrm{RuO}_{2}$ in commercial devices is restricted by its low abundance and high cost. For that reason, composites made with ruthenium oxide and carbon materials (activated carbon, nanotubes, mesoporous carbons, carbon aerogel, graphene, etc.) can be used to overcome all these limitations. 
The pioneering researches of Miller et al. [22,23] reported that the specific capacitance of a carbon aerogel is improved more than twice after the addition of hydrous ruthenium oxide (50 wt. \%) by a chemical vapor impregnation method (250 $\mathrm{F} \mathrm{g}^{-1}$ vs. $95 \mathrm{~F} \mathrm{~g}^{-1}$ ). Wang and Hu [24] prepared $\mathrm{RuO}_{2}$ (3.77 wt. \%)/activated carbon composites by wet impregnation and obtained a maximum capacitance of ca. $120 \mathrm{~F} \mathrm{~g}^{-1}$. A capacitance value of $231 \mathrm{~F} \mathrm{~g}^{-1}$ has been reported for a composite with 30.4 wt. \% of $\mathrm{RuO}_{2}$ prepared by direct reduction of $\mathrm{Ru}(\mathrm{VI})$ or $\mathrm{Ru}(\mathrm{VII})$ over functionalized carbon nanotubes $\left(\mathrm{RuO}_{2} / \mathrm{f}-\mathrm{MWCNTs}\right)$ [25]. While, a ruthenium oxide/mesoporous carbon composite prepared by impregnation technique reached a specific capacitance of $243 \mathrm{~F} \mathrm{~g}^{-1}$ with a loading of 54.3 wt. \% [26]. In addition, Rojo et al. [27] reported a capacitance value of about $250 \mathrm{~F} \mathrm{~g}^{-1}$ with a composite obtained by repetitive impregnation of amorphous carbon nanofibers with a ruthenium salt solution. However, the large contact resistance of the powder materials is a main concern on the design and construction of supercapacitors.

Activated carbon cloths or felts can be used to overcome this drawback without having to employ non-conductive binders. Besides, these materials have large specific areas, high conductivity and good structural strength [28-30]. Notwithstanding, there are few papers dealing with composites consisting of ruthenium oxide nanoparticles or films deposited on activated carbon cloth [31-33].

On the other hand, the use of electrochemical methods for the preparation of composite materials provides a number of advantages over other techniques. For example, the preparation procedure is simple and the growth of the film can be modulated by experimental parameters such as potential or applied current, the composition of the precursor solution and the deposition time [34-36]. 
The main purpose of this study is to analyze electrochemical deposition methods for producing flexible thin ruthenium oxide films deposited on an activated carbon cloth. The ruthenium oxide films were deposited on the carbon material by chronoamperometry, chronopotentiometry or cyclic voltammetry, and then were studied by scanning electron microscopy (SEM), transmission electron microscopy (TEM), X-ray photoelectron spectroscopy (XPS) and thermogravimetric analysis (TGA). The electrochemical behavior of the samples was characterized by cyclic voltammetry. The electrodes can be prepared through simple methods that can be easily implemented for production purposes and they are flexible and thin, the two main requirements for its use in a flexible and compact portable device.

\section{Experimental}

An activated carbon cloth provided by MAST Carbon (C-TEX27 woven) was used as the carbon material for the preparation of the composites. Porous texture of C-TEX27 was characterized by physical adsorption of $\mathrm{N}_{2}\left(-196{ }^{\circ} \mathrm{C}\right)$ and $\mathrm{CO} 2\left(0{ }^{\circ} \mathrm{C}\right)$, using an automatic adsorption system (Autosorb-6, Quantrachrome). The samples were outgassed at $250{ }^{\circ} \mathrm{C}$ under vacuum for $4 \mathrm{~h}$. Nitrogen adsorption results were used to determine BET surface area values and DubininRadushkevich (DR) micropore volumes (VDR $\mathrm{N}_{2}$ ) (pores of size below $2 \mathrm{~nm}$ ). The $\mathrm{CO}_{2}$ adsorption data at these conditions is used to calculate the narrow micropore volume (i.e. pores of size below $0.7 \mathrm{~nm}$ ) [37]. Temperature programmed desorption (TPD) experiments were done in a DSC-TGA equipment (TA Instruments, SDT 2960 Simultaneous) coupled to a mass spectrometer (Thermostar, Balzers, GSD 300 T3), to characterize the surface chemistry. In these experiments, $10 \mathrm{mg}$ of the sample were heated up to $950{ }^{\circ} \mathrm{C}$ (heating rate $20^{\circ} \mathrm{C} \mathrm{min}^{-1}$ ) under a helium flow rate of $100 \mathrm{ml} \mathrm{min}^{-1}$. The results are shown in Table 1. 
Ruthenium trichloride dihydrate was provided by Sigma-Adrich, while potassium chloride, hydrochloric and sulphuric acid were from Merck p.a. These reagents were used as received without further purification. All solutions were prepared with purified water obtained from an ElgaLab water Purelab system (18.2 $\mathrm{M} \Omega \mathrm{cm})$.

The electrolyte solution was prepared by dissolving ruthenium trichloride, potassium chloride and hydrochloric acid in ultrapure water to obtain a plating bath of $20 \mathrm{mM} \mathrm{RuCl}_{3}, 0.1 \mathrm{M} \mathrm{KCl}$ and $0.01 \mathrm{M} \mathrm{HCl}$, with an initial $\mathrm{pH}$ value kept at 2.0. The depositions were carried out at room temperature by cyclic voltammetry, chronoamperometry and chronopotentiometry over the activated carbon cloth (sample pieces of $2 \mathrm{~cm}^{2}$ of exposed geometrical area and $25 \mathrm{mg}$ ). Before the application of the electrochemical technique the samples were impregnated in the plating bath for 15 minutes. The experimental procedures are described in Table 2. After that, the composites were rinsed thoroughly several times with water and dried in an oven at $150{ }^{\circ} \mathrm{C}$ for 2 $\mathrm{h}$ in air. The mass of the electrodes was determined with a microbalance (SartoriusUltraMicrobalance, readability $=0.0001 \mathrm{mg}$ and permissible tolerance $= \pm 0.0007 \mathrm{mg}$ ).

The electrochemical characterization of the different electrodes was done by using a standard three-electrode cell configuration. Reversible hydrogen electrode (RHE), immersed in the same solution, was used as reference electrode and a spiral of platinum wire was employed as a counter electrode. $0.5 \mathrm{M} \mathrm{H}_{2} \mathrm{SO}_{4}$ solution was used as aqueous electrolyte. The electrolyte solution was degassed with nitrogen gas before measurements for 30 min and this nitrogen was passed over the solutions during the experiments The measurements were carried out with an EG\&G Potentiostat/Galvanostat model 273. The electrochemical behavior of the different electrodes was assessed by cyclic voltammetry (CV) at different scanning rates. The capacitance values were calculated from the interval between 0 and $1.0 \mathrm{~V}$ as follows: 


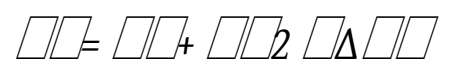

(1)

where $C_{\mathrm{s}}$ is the specific capacitance in $\mathrm{F}^{-1}, Q_{\mathrm{a}}$ and $Q_{\mathrm{c}}$ are the anodic and cathodic charges respectively in coulombs, $\Delta V$ is the voltage window in volts, $v$ is the scan rate in $\mathrm{V} \mathrm{s}^{-1}$ and $m$ is the weight of the sample in grams.

The obtained composites were characterized by SEM (Hitachi S3000N equipped with energy dispersive spectroscopy (EDS)) and TEM (JEOL JEM-2010) microscopies. XPS spectra were acquired with a VG-Microtech Mutilab 3000 equipment by employing $\mathrm{MgK \alpha}$ (1253.6 eV) irradiation as the photo source. The analysis chamber pressure during scans was approximately $5.10^{-7} \mathrm{~Pa}$.

Thermogravimetric (TG) analyses were carried out in air-flow $\left(50 \mathrm{ml} \mathrm{min}^{-1}\right)$ at a heating rate of $10{ }^{\circ} \mathrm{C} \mathrm{min}^{-1}$ with a Mettler Toledo TGA (SDTA851e/LF/1600) instrument. In all cases the weight of the composite was ca. $5 \mathrm{mg}$.

\section{Results and discussion}

3.1. Structural and thermal analysis characterization.

Fig. 1 shows the air-flow thermogravimetric (TG) curves recorded for C-TEX27 and some composites prepared by potentiostatic mode at $-0.5 \mathrm{~V}$. The combustion of the activated carbon cloth produces a significant weight loss at about $600{ }^{\circ} \mathrm{C}$, followed by a plateau associated with the ashes (low wt. \% residue) coming from the combustion of C-TEX27. For the composites the combustion temperature decreases up to $450{ }^{\circ} \mathrm{C}$ probably due the catalytic effect of the deposited $\mathrm{RuO}_{2}$ for carbon gasification [26,27]. In addition, it can also be seen that the composites have 
different residue content, which comes from the ashes of the activated carbon cloth as well as the $\mathrm{RuO}_{2}$. The loading of ruthenium oxide estimated from TGA was 5.0, 7.6, 10.8 and 14.6 wt. \% for deposition times of 15, 30, 60 and 120 min, respectively.

To investigate the surface morphology of the as-prepared C-TEX27/RuO $\mathrm{R}_{2}$ samples, SEM and TEM were employed. Fig. 2 shows the SEM images of a composite prepared by potentiostatic deposition at $-0.5 \mathrm{~V}$ for $60 \mathrm{~min}$. The top view of the composite indicates that the electrodeposition method creates a relatively compact and rough film, which follows the activated carbon cloth relief. Similar images were obtained with the other deposition times. The compact deposit seems to be formed by globular grains with sizes between 100 and $200 \mathrm{~nm}$. This porous structure is expected to provide a good access of the electrolyte solution through the entire thickness of the composite. In addition, over the compact deposit several islands formed by spherical grains can be also observed. The TEM image showed in Fig. 3 reveals that the globular $\mathrm{RuO}_{2}$ particles are in fact formed by crystallites of irregular shape with diameters between 3 and $5 \mathrm{~nm}$. The light regions correspond to porosity left in the ruthenium oxide film and the dark areas are the electrodeposited particles. Such structure of the film provides a threedimensional nanoporous network that may favor the proton transport into the inner ruthenium oxide structure, thus enhancing utilization of electro-active oxy-ruthenium species during faradic reactions.

To gain more insight into the characterization and to further have a complete picture of the CTEX27/RuO ${ }_{2}$ composites, XPS measurements were carried out. The XPS survey of an electrode synthesized by potentiostatic deposition confirms the presence of both ruthenium and oxygen atoms over the surface of the activated carbon cloth (Fig. 4a). Fig. 4b shows the O-1s core level spectrum and the corresponding deconvoluted peaks assigned to different oxygenated species. 
The major peak located at $530.08 \mathrm{eV}$ is associated with $\mathrm{Ru}-\mathrm{O}-\mathrm{Ru}$ species, the peak at $531.98 \mathrm{eV}$ is due to oxy-ruthenium species $(\mathrm{Ru}-\mathrm{OH})$ and the minor peak centered at $533.88 \mathrm{eV}$ is related to the water content of the deposit [38,39]. On the other hand, the XPS spectrum of the Ru-3p $\mathrm{p}_{3 / 2}$ core level can be deconvoluted into two peaks at $461.98 \mathrm{eV}$ and at $465.48 \mathrm{eV}$, respectively (Fig. 4c). The first peak is assigned to the presence of reduced ruthenium (zero valence) [40,41], while the second one is attributed to ruthenium dioxide or to mixed hydroxyl species with diverse coordination structure on the surface of $\mathrm{RuO}_{2}$ particles [24,38]. Fig. 4d shows the core level spectrum of Ru-3d $3 / 2$ and $\mathrm{Ru}-3 \mathrm{~d}_{5 / 2}$ signals that can be deconvoluted into two doublets separated by an energy gap of about $4 \mathrm{eV}$. The doublet whose peaks are centered at $280.98 \mathrm{eV}$ and 285.38 $\mathrm{eV}$, is assigned to ruthenium(IV) oxide [38]. Whereas, the peaks located at $280.18 \mathrm{eV}$ and 284.18 $\mathrm{eV}$ can be associated with the presence of $\mathrm{Ru}(0)$ [34]. Besides, the small peak at $284.88 \mathrm{eV}$ can be attributed to C-1s peak from graphite-like carbon atoms [42]. The above results indicate the existence of ruthenium dioxide $\left(\mathrm{RuO}_{2}\right.$ and $\left.\mathrm{RuO}_{2} \cdot x \mathrm{H}_{2} \mathrm{O}\right)$ and some amount of $\mathrm{Ru}(0)$ on the surface of the freshly prepared composites, in agreement with previous studies [17,43-45]. The presence of these hydrous ruthenium oxides is expected to improve the electrochemical reversibility and conductivity of the flexible composites. Furthermore, the $\mathrm{RuO}_{2}$ and Ru relative peak areas for the composites synthesized at constant potential, constant current or CV are very similar, suggesting that there is no major difference in electronic structure of the deposits.

\subsection{Electrochemical characterization.}

Fig. 5 shows the cyclic voltammograms of a C-TEX27 electrode and a C-TEX27/RuO ${ }_{2}$ composite electrode prepared by potentiostatic deposition at different potentials maintaining the deposition time. The voltammetric profile of the bare carbon material is quasi-rectangular in 
shape which indicates that the main contribution to capacitance is the charge/discharge process of the double layer. For the $\mathrm{RuO}_{2}$-containing composites, it can be observed that the voltammograms are mainly similar for deposition potentials of $-0.4 \mathrm{~V}$ and $-0.5 \mathrm{~V}$. However, a further decrease of the potential to $-0.6 \mathrm{~V}$ produces a slightly decrease of the voltammetric charge. This behavior can be attributed to the interference from hydrogen gas evolution on the film formation, i.e. the strong hydrogen evolution at this potential reduces the deposition efficiency of the metal incorporated on the activated carbon cloth.

The voltammetric current density for the C-TEX/ $\mathrm{RuO}_{2}$ composite electrodes is much larger than that for the bare electrode due to the reversible faradaic pseudocapacitance coming from the redox transitions of the interfacial electroactive species with different oxidation states at the ruthenium oxide deposit. According to Huković et al. [35], the surface redox process in the ruthenium oxide film takes place by the double ejection/injection of electrons and protons and the corresponding changes in the formal oxidation state of Ru atoms. Nevertheless, a recent report has indicated that the exceptional electrochemical capacitance of $\mathrm{RuO}_{2}$ is mainly assigned to proton intercalation within the layers of structural water at the subsurface and grain boundary effects instead of simple bulk or surface protonation process [46].

Fig. 6 compares the voltammograms obtained for the composite materials obtained with the three electrochemical methods and using the best experimental conditions to reach the highest capacitance. It can be observed that the voltammetric charge obtained with the potentiodynamic and galvanostatic methods are lower to that obtained with the potentiostatic method.

The voltammetric response observed in Fig. 6 for the electrode prepared by the potentiostatic method is similar to that reported for a thin film of ruthenium oxide [35,43-45]. On the positive 
scan direction it can be observed the hydrogen region in which the ionization of adsorbed hydrogen atoms overlaps with the adsorption of water on ruthenium atoms [43,44]. After that, there is a current plateau (between 0.25 and $0.75 \mathrm{~V}$ ), where surface oxidation by a reversible electrochemical reaction takes place. In this potential range co-exist $\mathrm{Ru}(\mathrm{I})$ and $\mathrm{Ru}(\mathrm{II})$ species as $\mathrm{RuOH}\left(\mathrm{H}_{2} \mathrm{O}\right)_{x}, \mathrm{RuO}, \mathrm{Ru}(\mathrm{OH})_{2}$ or $\mathrm{RuO} \cdot x \mathrm{H}_{2} \mathrm{O}[35,43,45]$. Then, the current density gradually increases due to the formation of ruthenium oxides of higher oxidation states $\left(\mathrm{Ru}_{2} \mathrm{O}_{3}\right.$ or $\mathrm{RuO}_{2} . x \mathrm{H}_{2} \mathrm{O}$ ) [35,43]. The presence of a cathodic peak centered at ca. $0.2 \mathrm{~V}$ can be distinguished during the reverse scan. This peak is usually associated with the partial oxide film reduction [44]. Besides, proton diffusion into defect sites, interstitial sites, and/or grain boundaries is also taking place in this potential region [47].

Table 3 shows the values of specific capacitance obtained for all the composites prepared by chronoamperometry (electrodes 1 to 4), cyclic voltammetry (electrode 5 and 6) and chronopotentiometry (electrode 7 to 9) techniques. These values permit to evaluate the influence of the electrochemical preparation method on the capacitance behavior of C-TEX27/RuO composites. The preparation method used for each electrode can be obtained from Table 2. At first inspection, it can be seen that the highest capacitance improvement is obtained with the composites synthesized in the potentiostatic mode (electrodes 1 to 4). For example, the specific capacitance of the composite prepared by potentiostatic deposition (-0.5 V for 60 min, electrode 3) increases $82 \%$ with respect to the bare electrode, while capacitance grows only about $43 \%$ for the composites obtained by potentiodynamic (electrodes 5 and 6) and galvanostatic modes (electrodes 7 to 9). The smaller capacitance value of the composite material prepared by potentiodynamic deposition can be associated with the repetitive rearrangement of the metal oxide deposits during cycling, which produces a less porous film and then reduces the reaction 
sites [34]. As a result, the penetration of the electrolyte through the metal oxide pores is restricted and the charge-transfer process may occur predominantly at the outermost surface of the electrode. This is in agreement with the observation that the voltammetric charge does not increase when the number of cycles increases from 50 to 100 cycles. On the other hand, the behavior of the electrodes prepared by galvanostatic conditions could be either related to the presence of a more compact film (i.e. less porous) [48] or to the presence of other side reactions like hydrogen evolution on the carbon electrode at the current used to prepare the composite.

The specific capacitance of the composites synthesized by potentiostatic conditions increases with deposition time because there is an increase in the number of active sites when the thickness of the film grows up (Table 3). That means that the increase in the amount of deposited ruthenium oxide seems to occur without appreciable blockage of the porosity in the activated carbon cloth, thus providing a high surface area for electrolyte penetration. The structure of the films provides the porosity and interconnectivity necessary for the access of electrolyte to both materials, which in turn plays a key role in the increase of the specific capacitance.

The shape of cyclic voltammograms remains almost unchanged with the increase of the scan rate, although the peaks become less defined (figure not shown). This behavior could be probably ascribed to a kinetically limited diffusion of protons into the composite pores (proton depletion) or as a consequence of proton accumulation within the porous of the composites (proton oversaturation) [23].

In the case of the potentiodynamic and galvanostatic methods, capacitance remains almost unchanged when the deposition is longer than $60 \mathrm{~min}$. This behavior could be caused by a diminution in the number of active sites for longer deposition times as a result of the fall-off in 
the porosity of the outer layer in the oxide film, limiting the available surface area of the electrode [16]. That is to say, as time goes on the ruthenium oxide is deposited in such a way that the pores are filled up either by crystal growth or by the nucleation of new particles. In view of the above results, it can be concluded that composites with improved capacitance can be successfully synthesized by potentiostatic deposition.

Fig. 7 shows the evolution of the specific capacitance at different scan rates for several composites prepared by potentiostatic mode. From Figure 7 it can be observed that, in all cases the capacitance decreases when the scan rate increases because of ion diffusion problems. It can be also observed that the specific capacitance of the composites increases when the deposition potential varies from -0.3 to $-0.5 \mathrm{~V}$, and then starts to decrease (electrode 3c). This behavior is similar to that observed for platinum deposition on a carbon material [49]. That is, the shift towards more negative potentials causes an increase in the oxide loading, the reduction in particle size, as well as the increase in film roughness. However, at more negative potentials there is a compromise between the formation of new particles and the hydrogen evolution reaction on the electrode surface. Therefore, the more violent the hydrogen evolution is, the smaller the number of new particles formed.

Moreover, it can be observed that the composites show a better performance with the scan rate that the pristine activated carbon. A decrease in capacitance of around $87 \%$ is obtained with the original activated carbon and a $66 \%$ for the electrode 4 .

In order to complete the information on the performance of the composites, we have checked if the specific capacitance obeys the rule of mixtures (Equation 1) [26]:

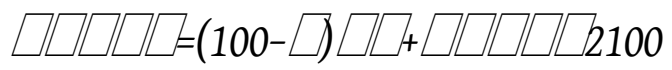


where $C_{\text {comp }}, C_{\mathrm{C}}$ and $C_{\mathrm{RuO} 2}$ are the specific capacitances of the composite, C-TEX27 and $\mathrm{RuO}_{2}$ respectively, and $\alpha$ is the $\mathrm{RuO}_{2}$ weight percentage determined from TGA analysis. The value used for $\mathrm{C}_{\mathrm{RuO2}}$ is $760 \mathrm{~F} \mathrm{~g}^{-1}$ obtained from the reference [50]. The experimental data follows the linear tendency predicted by eq. 1, thus the specific capacitance of all composites can be expressed as the sum of the specific capacitance provided by C-TEX27 and by deposited ruthenium oxide film. This suggests that the degree of ruthenium oxide utilization is very high and accessibility to the porous structure of the activated carbon cloth remains almost unaffected.

Finally, the performance of the composites was compared with some data reported in the literature. Jang et al. [26] have reported a specific capacitance of $177 \mathrm{~F} \mathrm{~g}^{-1}$ at a scan rate of $1 \mathrm{mV}$ $\mathrm{s}^{-1}$ with 14 wt. \% of $\mathrm{RuO}_{2}$ on mesoporous carbon. In the present paper a specific capacitance of $218 \mathrm{~F} \mathrm{~g}^{-1}$ has been obtained at $14.6 \mathrm{wt}$. \% loading at the same scan rate. Chen et al. [51] informed a specific capacitance value of $111.7 \mathrm{~F} \mathrm{~g}^{-1}$ at a scan rate of $25 \mathrm{mV} \mathrm{s}^{-1}$ for an activated carbon with a 10 wt. \% of $\mathrm{RuO}_{2}$ loading. Mitra et al. [52] reported a specific capacitance of about $176 \mathrm{~F}$ $\mathrm{g}^{-1}$ with $16.5 \mathrm{wt}$. \% Ru loading for exfoliated graphite-ruthenium oxide composites at $5 \mathrm{mV} \mathrm{s}^{-1}$ scan rate, while in this work, at the same scan rate a capacitance value of $191 \mathrm{~F} \mathrm{~g}^{-1}$ has been obtained with the composite of higher ruthenium oxide content. Reddy et al. [9] have obtained a specific capacitance of $138 \mathrm{~F} \mathrm{~g}^{-1}$ at $2 \mathrm{mV} \mathrm{s}^{-1}$ with a 20 wt. \% $\mathrm{RuO}_{2} / \mathrm{MWNTs}$ composite synthesized by chemical reduction. Also specific capacitance values between 90 and $130 \mathrm{~F} \mathrm{~g}^{-1}$ were determined for MWCNT based composites with 20 wt. \% of $\mathrm{RuO}_{2}$ prepared by chemical reduction and annealed at different temperatures [53]. Furthermore, a capacitance value of $153 \mathrm{~F}$ $\mathrm{g}^{-1}$ was reported by Miller and Dunn [23] for a carbon aerogel based composite with 18.5 wt. \% of $\mathrm{RuO}_{2}$. Then, the higher capacitance value of the materials synthesized in the present work can 
be mainly explained by the elevated $\mathrm{RuO}_{2}$ utilization due to the well-developed threedimensional nanoporous structure of the film prepared by electrochemical methods.

In addition, the specific energy $(S E)$ and specific power $(S P)$ of the flexible activated carbon cloth-ruthenium oxide composites have been calculated according to the following expressions:

$12 \square \square \Delta \square 2$

$12 \Delta \square \square \square \square$

The data obtained from the three-electrode configuration can be considered as the maximum performance of the flexible composite materials because it avoids the introduction of engineering issues coming from a two-electrode configuration (e.g., cell assembly, resistance from the separation film and electrolyte, coating homogeneity, etc.) [54]. Figure 8 shows the Ragone plots for some electrode materials over the entire scan rate range investigated in this work. The figure illustrates the typical behavior, with quasi-steady values of energy density at low and medium power density values, to then fall very quickly with increasing power density. It is worth noting that the maximum specific energy developed by the composites at the specific power of $0.1 \mathrm{~kW}$ $\mathrm{kg}^{-1}$ is in the range of 26 to $30 \mathrm{~W} \mathrm{~h} \mathrm{~kg}^{-1}$. In addition, it can be observed that the specific energy

remains as high as $10 \mathrm{~W} \mathrm{~h} \mathrm{~kg}$ when the specific power is increased to c.a. $3 \mathrm{~kW} \mathrm{~kg}^{-1}$, which is almost ten times higher than that of the C-TEX27 electrode.

\section{Conclusions}

Flexible activated carbon cloth-ruthenium oxide composites with high nanoporous structure can be successfully synthesized by different simple electrochemical techniques, including chronoamperometry, chronopotentiometry and cyclic voltammetry. The results show that the potentiostatic mode can be used to synthesize composites with higher specific capacitance than the pristine activated carbon cloth. It is worth noting that an improvement in capacitance of $82 \%$ and $100 \%$ with respect to the capacitance of the pristine activated carbon cloth could be obtained with low oxide content. This behavior has been interpreted in terms of the three- 
dimensional nanoporous structure of the film and the low particle size of the metal oxide. Then, capacitance values as high as $191 \mathrm{~F} \mathrm{~g}^{-1}$ for a composite containing 14.6 wt. \% have been obtained. It must be remarked that the use of activated carbon cloths avoids the use of any additional amount of binder and conductivity promoter and the combination with electrodeposition methods that provides a thin electrode with a high density and flexible.

\section{ACKNOWLEDGMENT}

Financial support by the Ministerio de Economía y Competitividad (MAT2010-15273) and Generalitat Valenciana and FEDER (PROMETEO/2009/047) projects are gratefully acknowledged. J.M.S. thanks Ministerio de Educación (SB2010-132).

\section{REFERENCES}

1. Barbir F. Transition to renewable energy systems with hydrogen as an energy carrier. Energy 34 (2009) 308-312.

2. Lund H. Renewable energy strategies for sustainable development. Energy 32 (2007) 912919.

3. Østergaard PA. Comparing electricity, heat and biogas storages’ impacts on renewable energy integration. Energy 37 (2012) 255-262.

4. Kaldellis JK, Zafirakis D. Optimum energy storage techniques for the improvement of renewable energy sources-based electricity generation economic efficiency. Energy 32 (2007) 2295-2305.

5. Masmoudi A, Abdelkafi A, Krichen L. Electric power generation based on variable speed wind turbine under load disturbance. Energy 36 (2011) 5016-5026.

6. Conway BE. Electrochemical Supercapacitors: Scientific Fundamentals and Technological Applications, New York, USA: Kluwer Academic/Plenum Publishers; 1999.

7. Reinhart Kühne. Electric buses - An energy efficient urban transportation means. Energy 35 (2010) 4510-4513. 
8. Wasselynck G, Auvity B, Olivier J-C, Trichet D, Josset C, Maindru P. Design and testing of a fuel cell powertrain with energy constraints. Energy 38 (2012) 414-424.

9. Naoi K, Simon P. New Materials and New Configurations for Advanced Electrochemical Capacitors. Interface (The Electrochemical Society), spring (2008) 34-37.

10. Abruña HD, Kiya Y, Henderson JC. Batteries and electrochemical capacitors. Phys. Today 61 (2008) 43-47.

11. Inagaki M, Konno K, Tanaike O. Carbon materials for electrochemical capacitors. J. Power Sources 195 (2010) 7880-7903.

12. Dubal DP, Holze R. All-solid-state flexible thin film supercapacitor based on $\mathrm{Mn}_{3} \mathrm{O}_{4}$ stacked nanosheets with gel electrolyte. Energy 51 (2013) 407-412.

13. Pech D, Brunet M, Durou H, Huang P, Mochalin V, Gogotsi Y, Taberna PL, Simon P. Ultrahigh-power micrometre-sized supercapacitors based on onion-like carbon. Nature Nanotechnology 5 (2010) 651-654.

14. Karandikar PB, Talange DB, Mhaskar UP, Bansal R. Development, modeling and characterization of aqueous metal oxide based supercapacitor. Energy 40 (2012) 131-138.

15. Ramani M, Haran BS, White RE, Popov BN, Arsov L, J. Power Sources 93 (2001) 209214.

16. Pico F, Ibañez J, Lillo-Rodenas MA, Linares-Solano A, Rojas RM, Amarilla JM, Rojo JM. Understanding $\mathrm{RuO}_{2} \cdot \mathrm{H}_{2} \mathrm{O} /$ carbon nanofibre composites as supercapacitor electrodes. J. Power Sources 176 (2008) 417-425.

17. Reddy ALM, Ramaprabhu S. Nanocrystalline Metal Oxides Dispersed Multiwalled Carbon Nanotubes as Supercapacitor Electrodes J. Phys. Chem. C 111 (2007) 7727-7734.

18. Park BO, Lokhande CD, Park HS, Jung KD, Joo OS. Performance of supercapacitor with electrodeposited ruthenium oxide film electrodes-effect of film thickness. J. Power Sources 134 (2004) 148-152.

19. Nam KW, Lee CW, Yang XQ, Choc BW, Yoond WS, Kim KB. Electrodeposited manganese oxides on three-dimensional carbon nanotube substrate: Supercapacitive behaviour in aqueous and organic electrolytes. J. Power Sources 188 (2009) 323-331.

20. Cross A, Morel A, Cormie A, Hollenkamp T, Donne S. Enhanced manganese dioxide supercapacitor electrodes produced by electrodeposition J. Power Sources 196 (2011) 7847-7853. 
21. Babakhani B, Ivey DG. Anodic deposition of manganese oxide electrodes with rod-like structures for application as electrochemical capacitors. J. Power Sources 195 (2010) 2110-2117.

22. Miller JM, Dunn B, Tran TD, Pekala RW. Deposition of Ruthenium Nanoparticles on Carbon Aerogels for High Energy Density Supercapacitor Electrodes. J. Electrochem. Soc. 144 (1997) L309-L311.

23. Miller JM, Dunn B. Morphology and Electrochemistry of Ruthenium/Carbon Aerogel Nanostructures. Langmuir 15 (1999) 799-806.

24. Wang CC, Hu CC. The capacitive performance of activated carbon-ruthenium oxide composites for supercapacitors: effects of ultrasonic treatment in $\mathrm{NaOH}$ and annealing in air. Mater. Chem. Phys. 83 (2004) 289-297.

25. Liu X, Huber TA, Kopac MC, Pickup PG. Ru oxide/carbon nanotube composites for supercapacitors prepared by spontaneous reduction of $\mathrm{Ru}(\mathrm{VI})$ and $\mathrm{Ru}(\mathrm{VII})$. Electrochim. Acta 54 (2009) 7141-7147.

26. Jang JH, Han S, Hyeon T, Oh SM. Electrochemical capacitor performance of hydrous ruthenium oxide/mesoporous carbon composite electrodes. J. Power Sources 123 (2003) 79-85.

27. Barranco V, Pico F, Ibañez J, Lillo-Rodenas MA, Linares-Solano A, Kimura M, Oya A, Rojas RM, Amarilla JM, Rojo JM. Amorphous carbon nanofibres inducing high specific capacitance of deposited hydrous ruthenium oxide. Electrochim. Acta 54 (2009) 74527457.

28. Ishikawa M, Sakamoto A, Morita M, Matsuda Y, Ishida K. Effect of treatment of activated carbon fiber cloth electrodes with cold plasma upon performance of electric double-layer capacitors. J. Power Sources 60 (1996) 233-238.

29. Milczarek G, Ciszewski A, Stepniak I. Oxygen-doped activated carbon fiber cloth as electrode material for electrochemical capacitor. J. Power Sources 196 (2011) 78827885.

30. Xu B, Wu F, Chen S, Zhang C, Cao G, Y. Yang. Activated carbon fiber cloths as electrodes for high performance electric double layer capacitors. Electrochim. Acta 52 (2007) 4595-4598. 
31. Wang CC, Hu CC. Electrochemical catalytic modification of activated carbon fabrics by ruthenium chloride for supercapacitors. Carbon 43 (2005) 1926-1935.

32. Liu X, Pickup PG. Thin Film Ru Oxide/Carbon Fabric Composites for Supercapacitors. J. Electrochem. Soc. 158 (2011) A241-A249.

33. Liu X, Pickup PG. Ru oxide/carbon Fabric Composites for Supercapacitors. J. Solid State Electrochem. 14 (2010) 231-240.

34. Jow JJ, Lee HJ, Chen HR, Wu MS, Wei TY. Anodic, cathodic and cyclic voltammetric deposition of ruthenium oxides from aqueous $\mathrm{RuCl}_{3}$ solutions. Electrochim. Acta 52 (2007) 2625-2633.

35. Metikoš-Huković M, Babić R, Jović F, Grubač Z. Anodically formed oxide films and oxygen reduction on electrodeposited ruthenium in acid solution. Electrochim. Acta 51 (2006) 1157-1164.

36. Domínguez-Dominguez S, Arias-Pardilla J, Berenguer-Murcia A, Morallón E, CazorlaAmorós D. Electrochemical deposition of platinum nanoparticles on different carbon supports and conducting polymers. J. Appl. Electrochem. 38 (2008) 259-268.

37. Cazorla-Amorós D, Alcañiz-Monge J, Linares-Solano A. Characterisation of Activated Carbon Fibres by $\mathrm{CO}_{2}$ Adsorption. Langmuir 12 (1996) 2820-2824.

38. Suñol JJ, Bonneau ME, Roué L, Guay D, Schulz R. XPS surface study of nanocrystalline Ti-Ru-Fe materials. Appl. Surf. Sci. 158 (2000) 252-262.

39. Kötz R, Lewerenz HJ, Stucki S. XPS Studies of Oxygen Evolution on Ru and $\mathrm{RuO}_{2}$ Anodes. J. Electrochem. Soc. 130 (1983) 825-829.

40. Nurunnabi M, Murata K, Okabe K, Inaba M, Takahara I. Performance and characterization of $\mathrm{Ru} / \mathrm{Al}_{2} \mathrm{O}_{3}$ and $\mathrm{Ru} / \mathrm{SiO}_{2}$ catalysts modified with $\mathrm{Mn}$ for FischerTropsch synthesis. Appl. Catal. A 340 (2008) 203-211.

41. Liu F, Yan Q, Zhou WJ, Zhao XS, Lee JY. High Regularity Porous Oxophilic Metal Films on Pt as Model Bifunctional Catalysts for Methanol Oxidation. Chem. Mater. 18 (2006) 4328-4335.

42. Larsen MJ, Skou EM. ESR, XPS, and thin-film RRDE characterization of nano structured carbon materials for catalyst support in PEM fuel cells. J. Power Sources 202 (2012) 35-46. 
43. Vuković M, Čukman D. Electrochemical quartz crystal microbalance study of electrodeposited ruthenium. J. Electroanal. Chem. 474 (1999) 167-173.

44. Hadži-Jordanov S, Angerstein-Kozlowska H, Vuković M, Conway BE. The state of electrodeposited hydrogen at ruthenium electrodes. J. Phys. Chem. 81 (1977) 2271-2279.

45. Horvat-Radošević V, Kvastek K, Vuković M, Čukman D. Electrochemical properties of ruthenised electrodes in the oxide layer region. J. Electroanal. Chem. 482 (2000) 188201.

46. Liu Y, Zhou F, Ozolins V. Ab Initio Study of the Charge-Storage Mechanisms in $\mathrm{RuO}_{2}$ Based Electrochemical Ultracapacitors. J. Phys. Chem. C 116 (2012) 1450-1457.

47. Sugimoto W, Iwata H, Yokoshima K, Murakami Y, Takasu Y. Proton and Electron Conductivity in Hydrous Ruthenium Oxides Evaluated by Electrochemical Impedance Spectroscopy: The Origin of Large Capacitance. J. Phys. Chem. B 109 (2005) 7330-7338.

48. Dubal DP, Dhawale DS, Gujar TP, Lokhande CD. Effect of different modes of electrodeposition on supercapacitive properties of $\mathrm{MnO}_{2}$ thin films. Appl. Surf. Sci. 257 (2011) 3378-3382.

49. Duarte MME, Pilla AS, Sieben JM, Mayer CE. Platinum particles electrodeposition on carbon substrates. Electrochem. Commun. 8 (2006) 159-164.

50. Jow TR, Zheng JP. Electrochemical Capacitors Using Hydrous Ruthenium Oxide and Hydrogen Inserted Ruthenium Oxide. J. Electrochem. Soc. 145 (1998) 49-52.

51. Chen WC, Hu CC, Wang CC, Min CK. Electrochemical characterization of activated carbon-ruthenium oxide nanoparticles composites for supercapacitors. J. Power Sources 125 (2004) 292-298.

52. Mitra S, Lokesh KS, Sampath S. Exfoliated graphite-ruthenium oxide composite electrodes for electrochemical Supercapacitors. J. Power Sources 185 (2008) 1544-1549.

53. Seo MK, Saouab A, Park SJ. Effect of annealing temperature on electrochemical characteristics of ruthenium oxide/multi-walled carbon nanotube composites. Mater. Sci. Eng. B 167 (2010) 65-69.

54. Lin KM, Chang KH, Hu C-C, Li YY. Mesoporous $\mathrm{RuO}_{2}$ for the next generation supercapacitors with an ultrahigh power density. Electrochim. Acta 54 (2009) 4574-4581. 


\section{FIGURE CAPTIONS}

Figure 1. TGA curves of C-TEX27 (solid line) and various C-TEX27/ $\mathrm{RuO}_{2}$ composites prepared by potentiostatic deposition at $-0.5 \mathrm{~V}$ with different deposition times: $15 \mathrm{~min}$ (dash line), 30 min (dot line), 60 min (dash-dot line) and 120 min (short-dash line).

Figure 2. Scanning electron micrographs (SEM) of a C-TEX27/RuO ${ }_{2}$ composite prepared by potentiostatic deposition. Magnification: 500X (a), 5000X (b).

Figure 3. TEM image of a $\mathrm{RuO}_{2}$ thin film formed on the activated carbon cloth.

Figure 4. X-ray photoelectron spectrum survey (a) and the XPS spectra of O-1s (b), Ru 3 $\mathrm{p}_{3 / 2,1 / 2}$ (c) and $\mathrm{Ru} 3 \mathrm{~d}_{5 / 2,3 / 2}$ (d) of the $\mathrm{RuO}_{2}$ film formed potentiostatically at $-0.5 \mathrm{~V}$ for 60 min on the activated carbon cloth.

Figure 5. Three-electrode stabilized cyclic voltammograms of C-TEX27 (solid thick line) and CTEX27/RuO $\mathrm{R}_{2}$ electrodes in $0.5 \mathrm{M} \mathrm{H}_{2} \mathrm{SO}_{4}$ prepared by potentiostatic method at room temperature, using the same deposition time (60 min) but different deposition potentials. $\mathrm{E}=-0.3$ $\mathrm{V}$ (dashed-dotted line), $\mathrm{E}=-0.4 \mathrm{~V}$ (dotted line), $\mathrm{E}=-0.5 \mathrm{~V}$ (dashed line) and $\mathrm{E}=-0.6 \mathrm{~V}$ (solid thin line).

Figure 6. Three-electrode stabilized cyclic voltammograms of C-TEX27 (solid thick line) and CTEX27/RuO 2 electrodes in $0.5 \mathrm{M} \mathrm{H}_{2} \mathrm{SO}_{4}$ synthesized using different electrochemical deposition methods at room temperature. (solid thin line) potentiostatic deposition at -0.5 V during $120 \mathrm{~min}$, (dashed line) potentiodynamic deposition at $50 \mathrm{mV} \mathrm{s}^{-1}$ between $-0.5 \mathrm{~V}$ and $1.2 \mathrm{~V}$ during 100 cycles, (dotted line) galvanostatic deposition at -15 mA during 120 min. 
Figure 7. Specific capacitance variation with increase of scan rate of $\mathrm{CV}$ in $0.5 \mathrm{M} \mathrm{H}_{2} \mathrm{SO}_{4}$. CTEX27/RuO 2 composites prepared by potentiostatic deposition described in Table 2.

Figure 8. Ragone plot related to energy and power densities of samples 0 (C-TEX27), 3 (C$\left.\mathrm{TEX} 27 / \mathrm{RuO}_{2}, \mathrm{E}=-0.5 \mathrm{~V} \mathrm{t}=60 \mathrm{~min}\right)$ and $4\left(\mathrm{C}-\mathrm{TEX} 27 / \mathrm{RuO}_{2}, \mathrm{E}=-0.5 \mathrm{~V} \mathrm{t}=120 \mathrm{~min}\right)$ at a voltage window of $1 \mathrm{~V}(0-1 \mathrm{~V})$. 
Table 1. Porous texture characterization and quantification of surface oxygen groups (TPD experiments) of the activated carbon cloth.

\begin{tabular}{|c|c|c|c|c|c|c|c|}
\hline Sample & $\begin{array}{l}\mathrm{S}_{\mathrm{BET}} / \\
\mathrm{m}^{2} \mathrm{~g}^{-1}\end{array}$ & $\begin{array}{c}\mathrm{V}_{\mathrm{DR}(\mathrm{N} 2)} \\
\mathrm{cm}^{3} \mathrm{~g}^{-1}\end{array}$ & $\begin{array}{c}\mathrm{V}_{\mathrm{DR}(\mathrm{CO} 2)} \\
\mathrm{cm}^{3} \mathrm{~g}^{-1}\end{array}$ & $\begin{array}{c}\mathrm{CO} / \\
\mu \mathrm{mol} \mathrm{g}^{-1}\end{array}$ & $\begin{array}{c}\mathrm{CO}_{2} \\
\mu \mathrm{mol} / \mathrm{g}^{-1}\end{array}$ & $\begin{array}{c}\mathrm{O} / \\
\mu \mathrm{mol} \mathrm{g}^{-1}\end{array}$ & $\begin{array}{c}\rho / \\
\mathrm{g} \mathrm{m}^{-2}\end{array}$ \\
\hline C-TEX27 & 1064 & 0.48 & 0.39 & 969 & 786 & 2541 & 110 \\
\hline
\end{tabular}

Table 2. Electrodeposition methods used to prepare the C-TEX27/ $\mathrm{RuO}_{2}$ composites. Ruthenium deposition was performed from $20 \mathrm{mM} \mathrm{RuCl}_{3}$ in $0.1 \mathrm{M} \mathrm{KCl}+0.01 \mathrm{M} \mathrm{HCl}(\mathrm{pH}=2)$.

\begin{tabular}{c|c|c|c}
\multicolumn{2}{c|}{ Synthesis procedure } & $\begin{array}{c}\mathrm{t}_{\text {impregnation }} \\
\text { min }\end{array}$ & $\begin{array}{c}\text { Electrode } \\
\mathrm{N}^{\circ}\end{array}$ \\
& $\mathrm{t}=15 \mathrm{~min}$ & 15 & 1 \\
$\mathrm{E}=-0.5 \mathrm{~V}$ & $\mathrm{t}=30 \mathrm{~min}$ & 15 & 2 \\
& $\mathrm{t}=60 \mathrm{~min}$ & 15 & 3 \\
\hline $\mathrm{E}=-0.3 \mathrm{~V}$ & $\mathrm{t}=60 \mathrm{~min}$ & 15 & 4 \\
$\mathrm{E}=-0.4 \mathrm{~V}$ & $\mathrm{t}=60 \mathrm{~min}$ & 15 & $3 \mathrm{~b}$ \\
$\mathrm{E}=-0.6 \mathrm{~V}$ & $\mathrm{t}=60 \mathrm{~min}$ & 15 & $3 \mathrm{c}$ \\
\hline $\mathrm{E}_{\mathrm{i}}=-0.5 \mathrm{~V}, \mathrm{E}_{\mathrm{f}}=1.2 \mathrm{~V}$ & 50 cycles & 15 & 5 \\
$\mathrm{U}=50 \mathrm{mV} \mathrm{s}$ & 100 cycles & 15 & 6 \\
\hline $\mathrm{I}=-15 \mathrm{~mA}$ & $\mathrm{t}=60 \mathrm{~min}$ & 15 & 8 \\
\hline & $\mathrm{t}=120 \mathrm{~min}$ & 15 & 9 \\
\hline
\end{tabular}


Table 3. Capacitance of the composites obtained by cyclic voltammetry at a scan rate $10 \mathrm{mV} \mathrm{s}^{-1}$.

\begin{tabular}{|c|c|c|c|}
\hline $\begin{array}{c}\text { Electrode } \\
\mathrm{N}^{\circ}\end{array}$ & Material & $\begin{array}{l}\mathrm{C}_{\mathrm{s}} / \\
\mathrm{F} \mathrm{g}^{-1}\end{array}$ & $\begin{array}{c}\text { Capacitance } \\
\text { improvement \% }\end{array}$ \\
\hline 0 & C-TEX27 & 90 & - \\
\hline 1 & $\mathrm{C}-\mathrm{TEX} 27 / \mathrm{RuO}_{2}$ & 114 & 27 \\
\hline 2 & $\mathrm{C}-\mathrm{TEX} 27 / \mathrm{RuO}_{2}$ & 136 & 52 \\
\hline 3 & $\mathrm{C}-\mathrm{TEX} 27 / \mathrm{RuO}_{2}$ & 164 & 82 \\
\hline 4 & $\mathrm{C}-\mathrm{TEX} 27 / \mathrm{RuO}_{2}$ & 180 & 100 \\
\hline 5 & $\mathrm{C}-\mathrm{TEX} 27 / \mathrm{RuO}_{2}$ & 127 & 42 \\
\hline 6 & $\mathrm{C}-\mathrm{TEX} 27 / \mathrm{RuO}_{2}$ & 129 & 44 \\
\hline 7 & $\mathrm{C}-\mathrm{TEX} 27 / \mathrm{RuO}_{2}$ & 131 & 46 \\
\hline 8 & $\mathrm{C}-\mathrm{TEX} 27 / \mathrm{RuO}_{2}$ & 129 & 45 \\
\hline 9 & $\mathrm{C}-\mathrm{TEX} 27 / \mathrm{RuO}_{2}$ & 130 & 44 \\
\hline
\end{tabular}




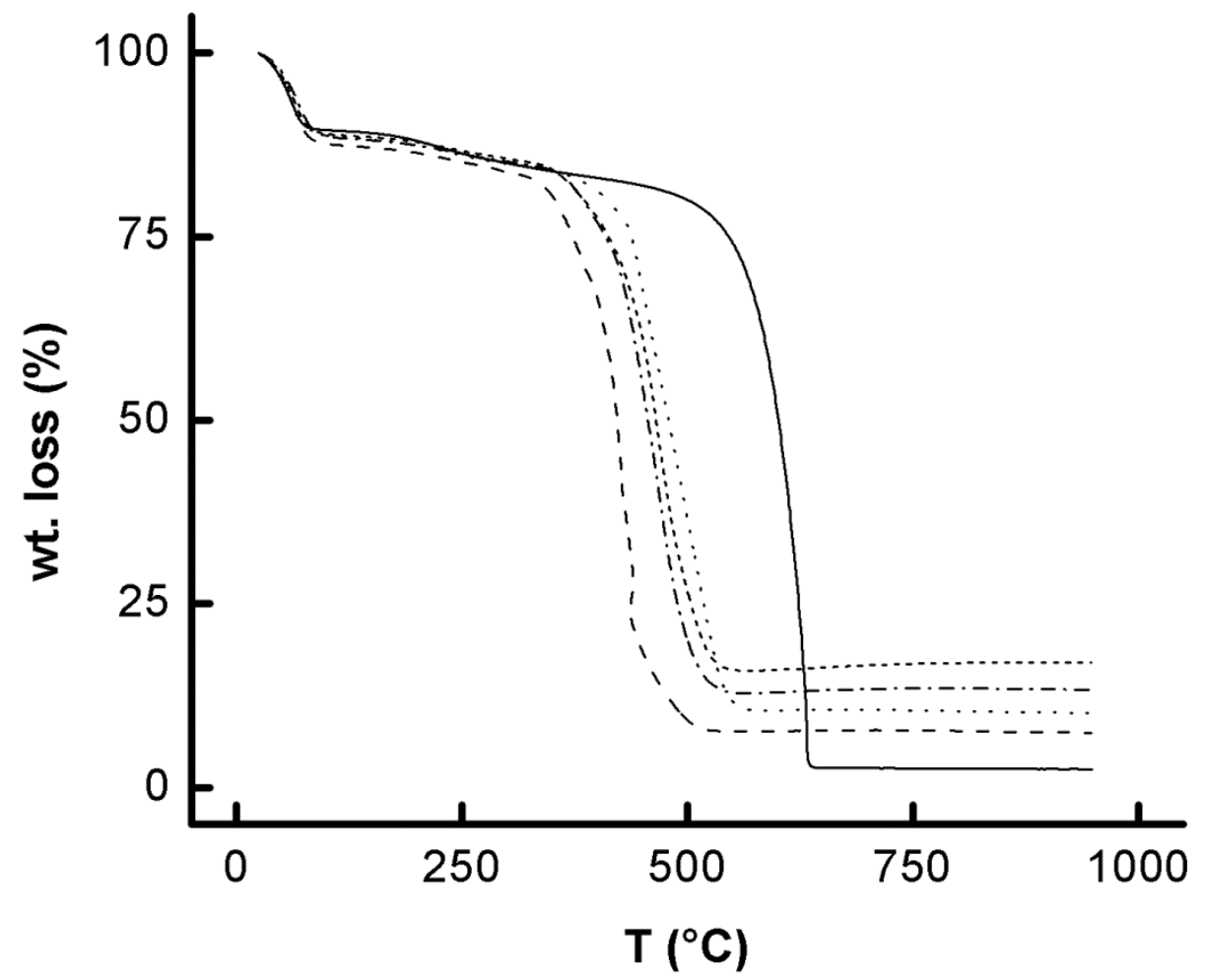

Figure 1 

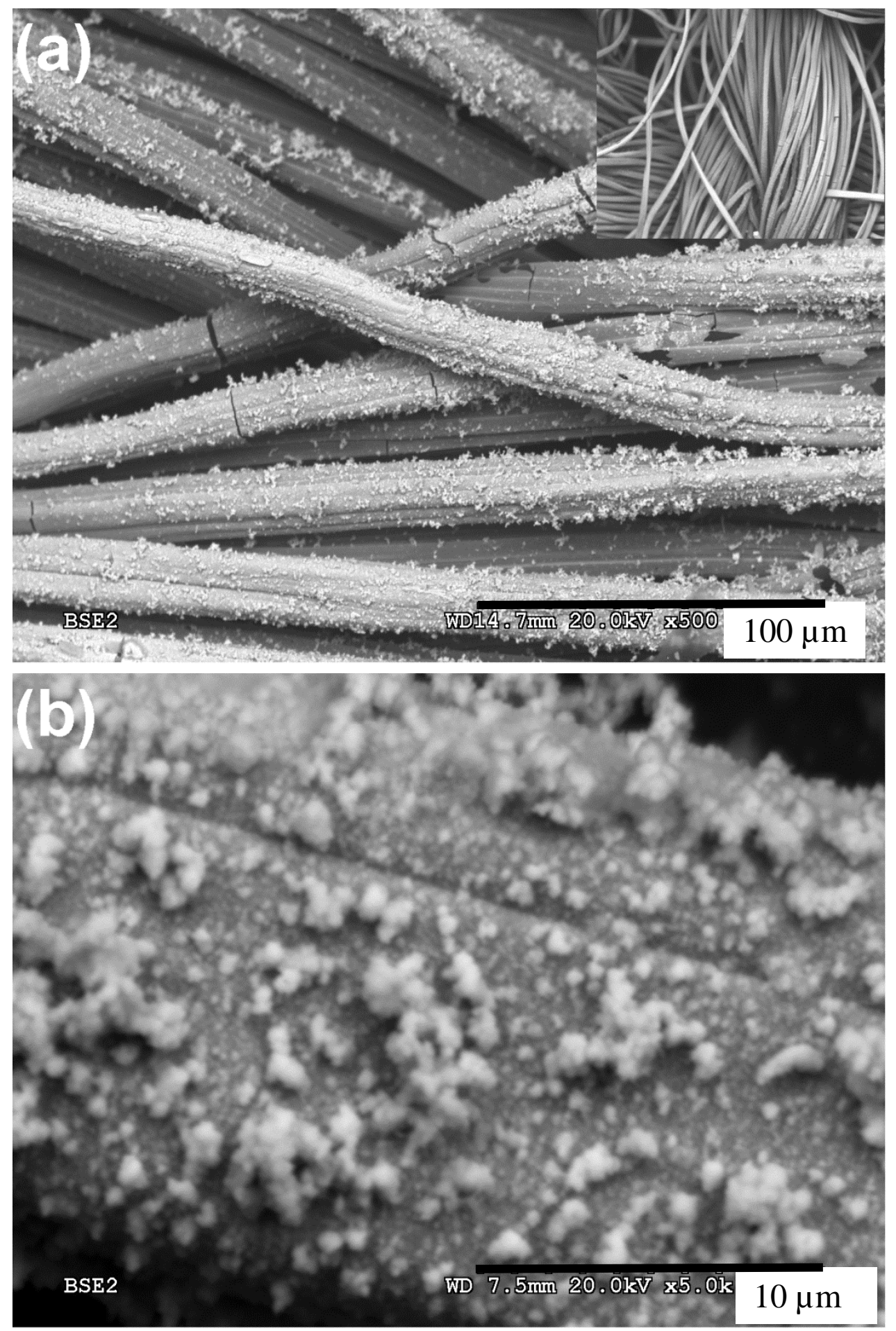

Figure 2 


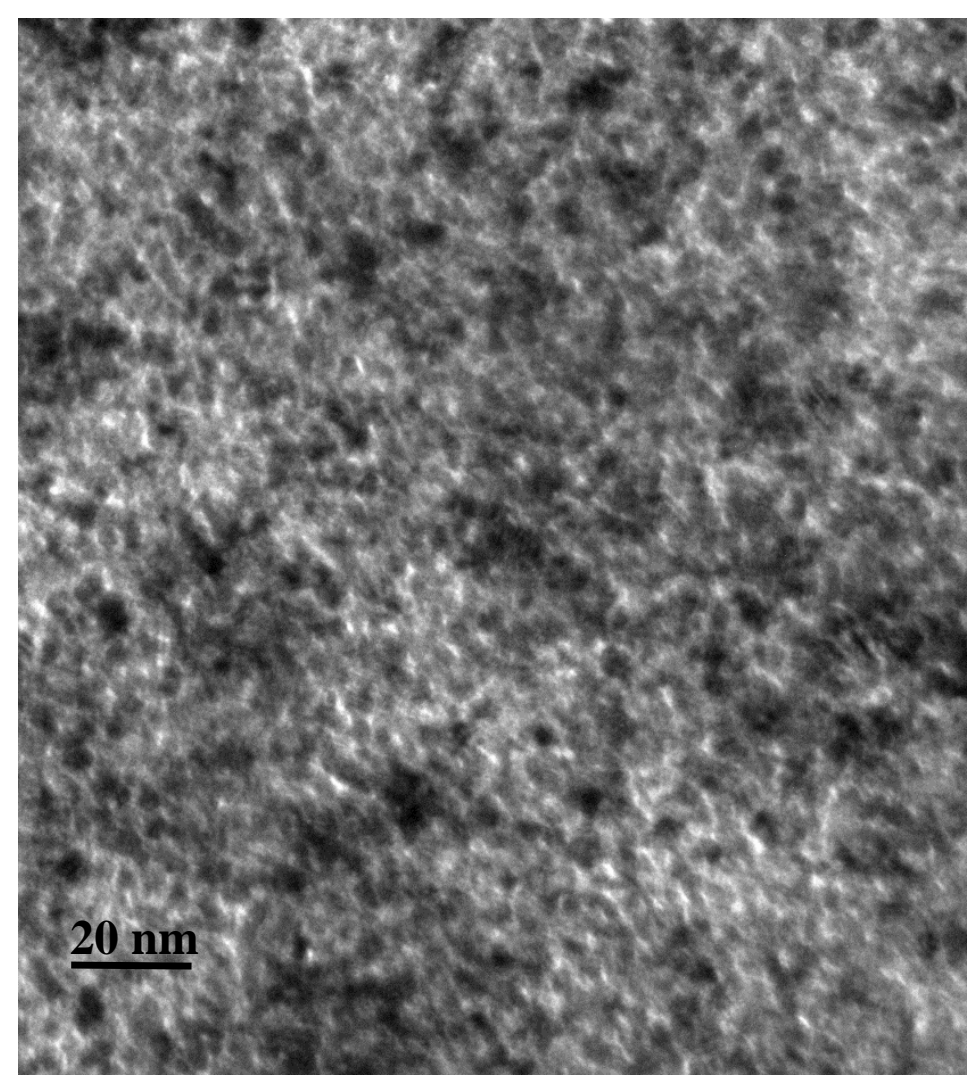

Figure 3 

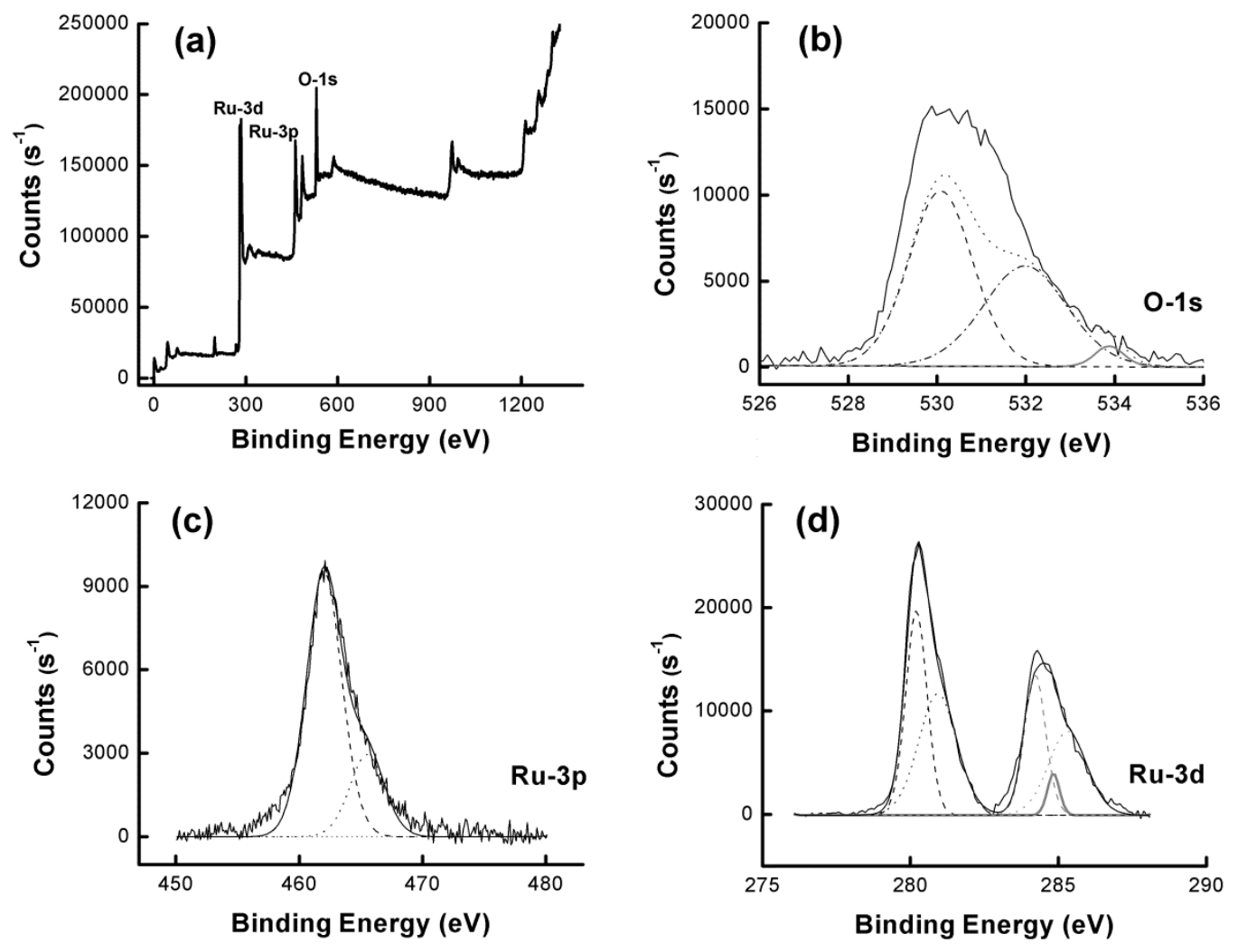

Figure 4 


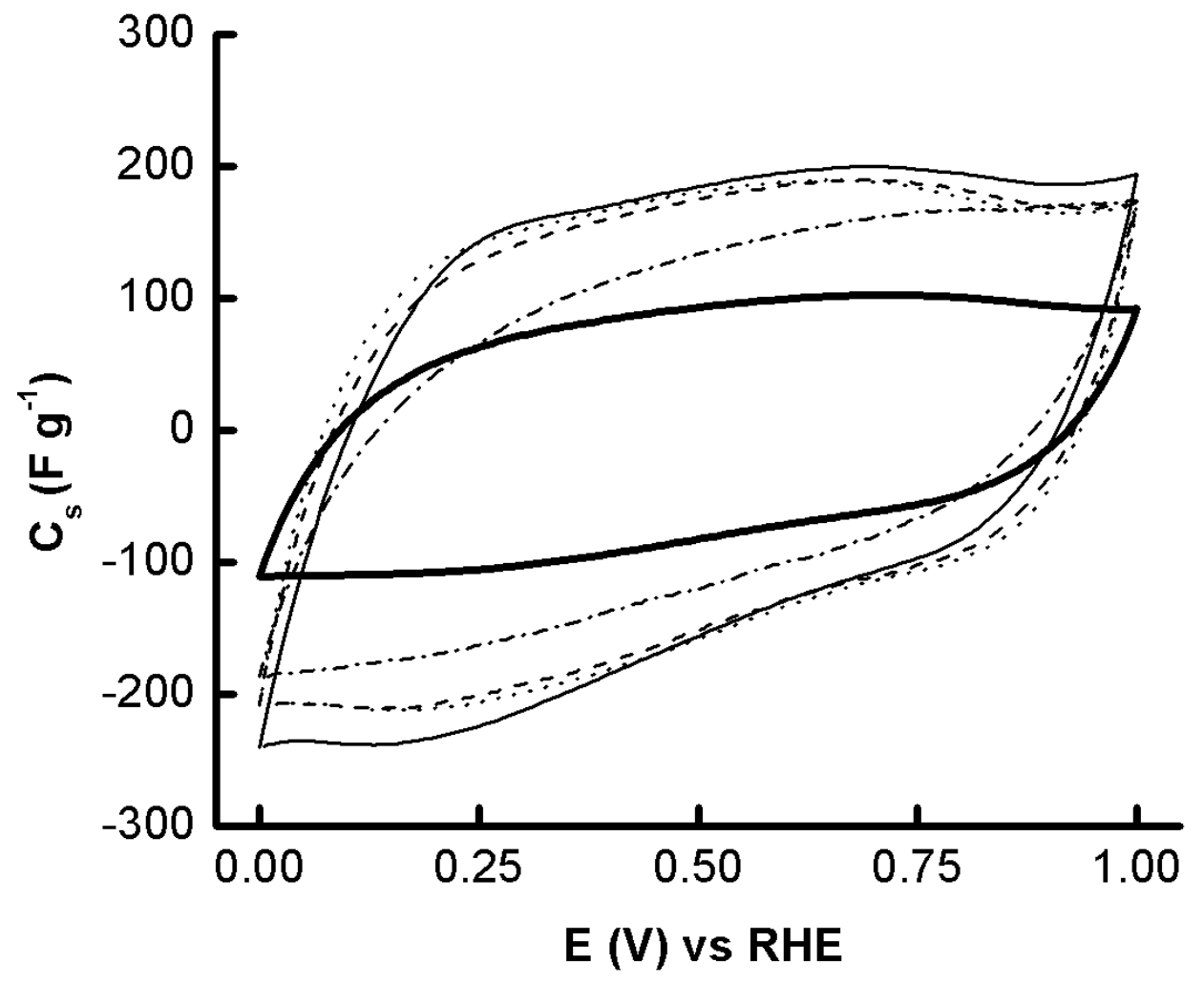

Figure 5 


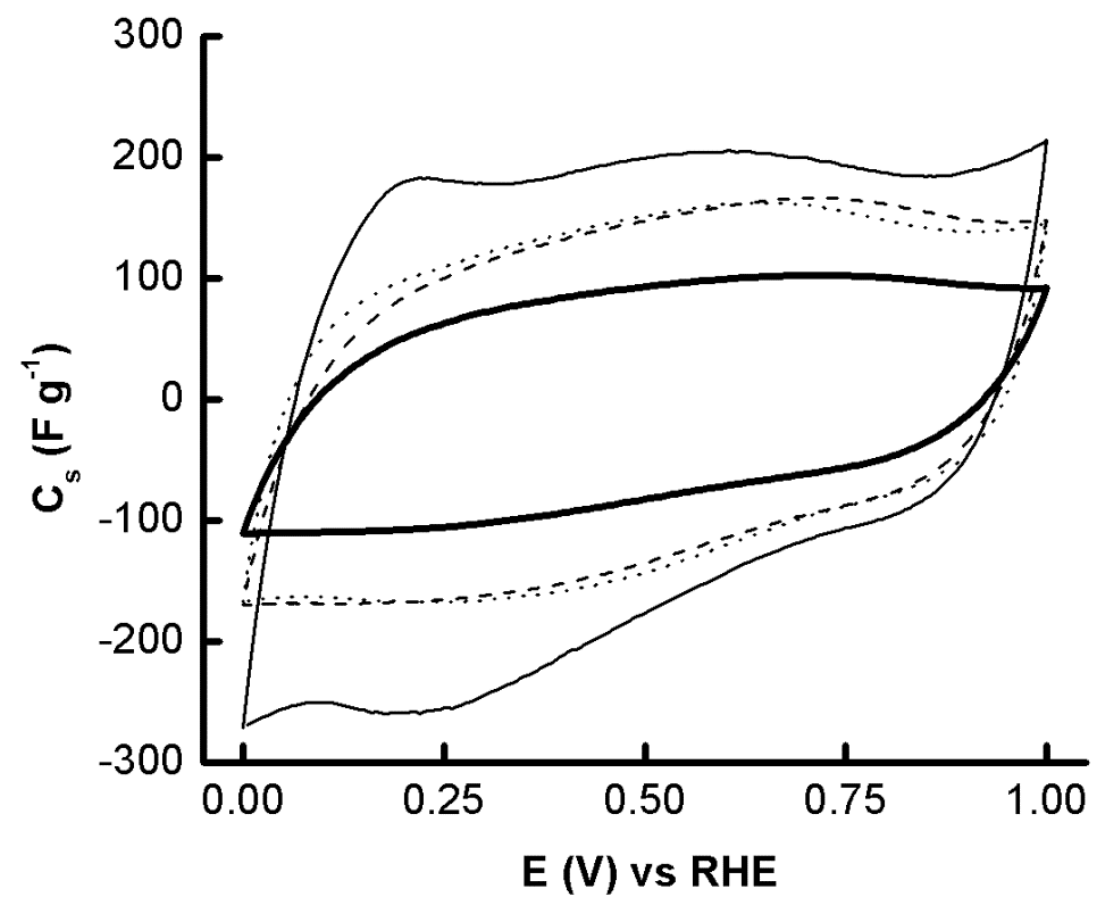

Figure 6 


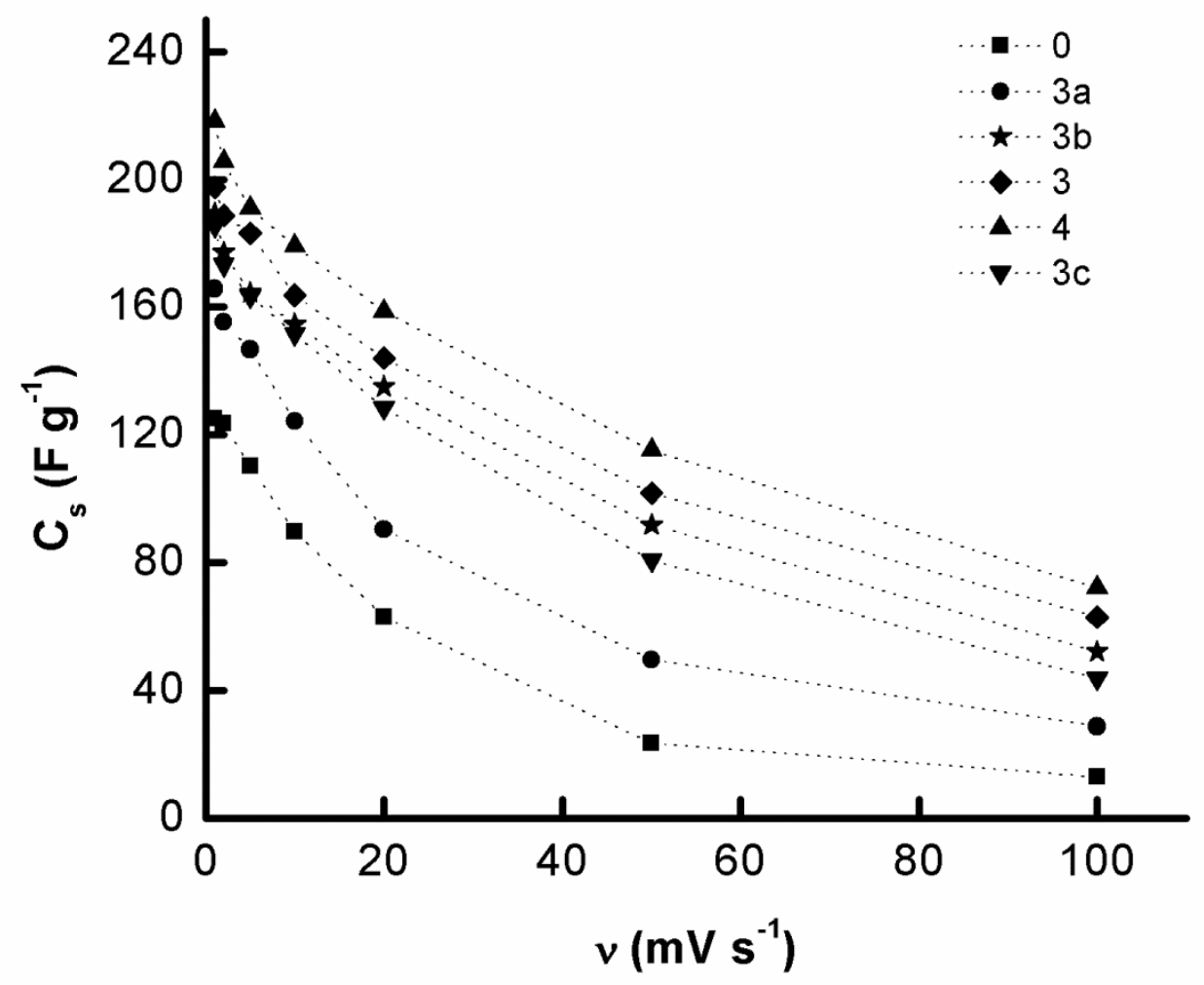

Figure 7 


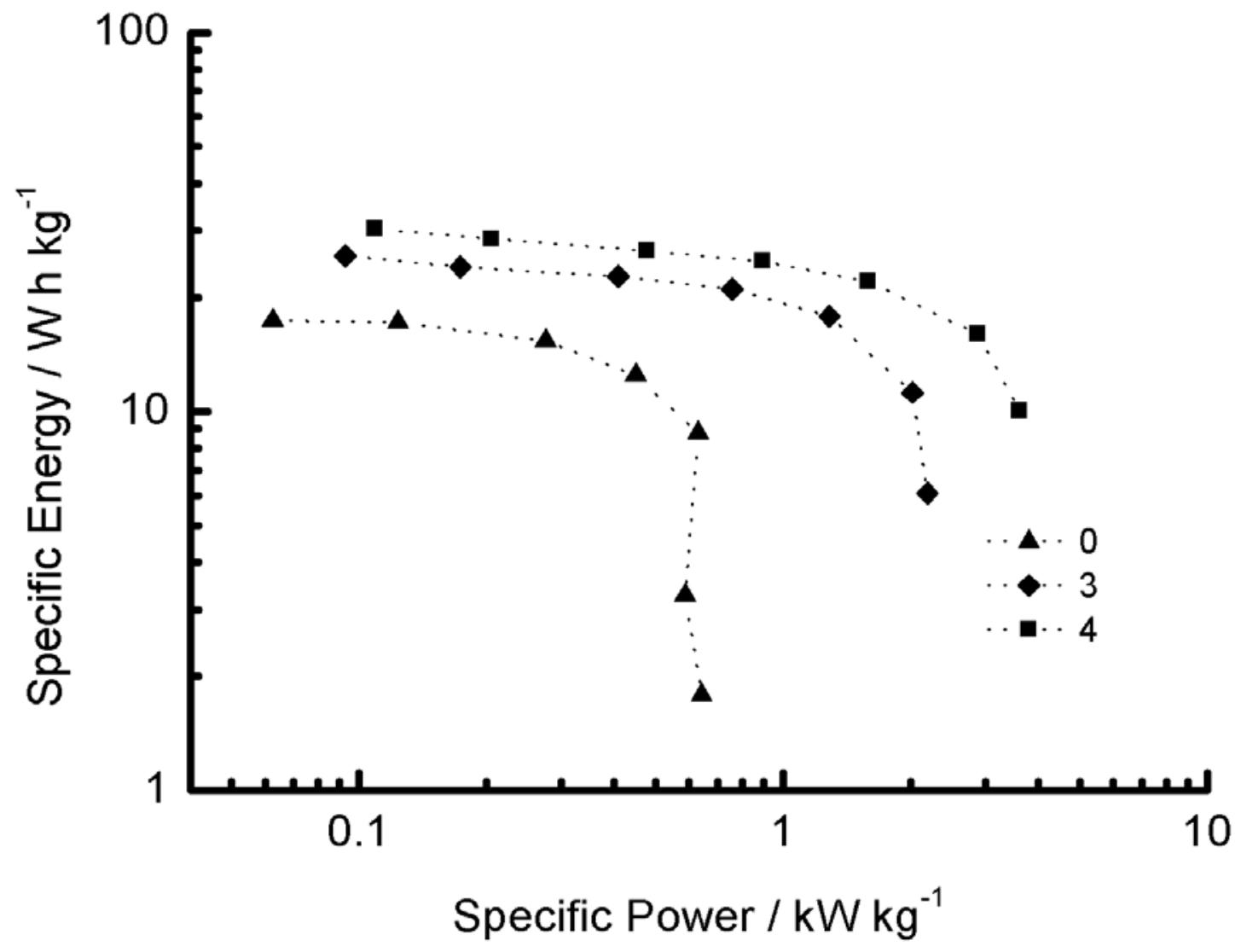

Figure 8 